\title{
HIERARCHY OF EUSTRESS AND DISTRESS: RASCH CALIBRATION OF THE VALENCIA EUSTRESS-DISTRESS APPRAISAL SCALE ${ }^{1}$
}

\author{
Malgorzata W. Kozusznik, Susana Lloret, Isabel Rodríguez, José M. Peiró
}

\begin{abstract}
The purpose of the study was to uncover the hierarchy of eustress and distress appraisal and calibrate the Valencia Eustress Distress Appraisal Scale (VEDAS, Rodríguez, Kozusznik, \& Peiró, 2013) using the Rasch Analysis (RA). A cross-sectional study was conducted on sample of 603 Spanish social service professionals. The VEDAS included four subscales addressing work demands that can be appraised as sources of eustress and distress. RA was carried out for eustress and distress appraisal scales. A graduation of stressful situations appraised as distress and/or as eustress was revealed. One of the greatest sources of distress and one of the lesser sources of eustress was "switching off at home". Situations involving personal accountability were considered both most severe sources of distress and the most important source of eustress. Work-life interactions involving other persons outside work were considered least severe sources of distress and least important sources of eustress. The results empirically support previous theoretical considerations of the coexistence of eustress and distress appraisals of the same demands applying advances in measurement. Implications of the calibration of stress appraisal for theory and organizational practice as well as the benefits of applying RA in occupational psychology research are discussed.
\end{abstract}

\section{Keywords}

Stress appraisal, eustress, distress, Rasch analysis, IRT.

Occupational stress often has detrimental effects on both employees' health and work outcomes (Gabriel, Diefendorff, \& Erickson, 2011; Ganser \& Rosen, 2013; Meier, Gross, Spector, \& Semmer, 2013) and companies' performance and costs (Podsakoff, LePine, \& LePine, 2007). In the European Union, one in four workers is negatively affected by stress (Eurofound and EU-OSHA, 2014). However, the negative consequences of stress is only half a picture, since the positive psychology approach shows that positive stress experiences may entail favorable outcomes (Cavanaugh, Boswell, Roehling, \& Boudreau, 2000; Sonnentag, Mojza, Demerouti, \& Bakker, 2012), such as well-being, work satisfaction, and organizational commitment (Scheck, Kinicki, \& Davy, 1997). This positive view of stress, referred to as eustress, emphasizes the productive activation and vital energy (Schwarzer \& Knoll, 2003). In contrast, stress experiences that are mainly related to negative emotions and strain have been labeled as distress.

\footnotetext{
1 This research is part of "Work stress: opportunity or threat? A study of work stress and individual and collective coping" funded by the Generalitat Valenciana, Spain (GV05/016). The preparation of the MS has been supported by the Project PSI2012-36557 of the Spanish Ministry and by the PROMETEO 2012/048 Project granted by the Valencian Regional Ministry. The authors declare that they have no conflict of interest. Correspondence concerning this article should be addressed to José María Peiró, Research Institute IDOCAL, Facultad de Psicología, Av. Blasco Ibañez, 21, 46010 Valencia, Spain. E-mail: jose.m.peiro@uv.es Tel: (+34)963864689, Fax (+34)963864668.
} 
Stress is the whole process from stressor to strain, strain being a response to the stressor (Griffin \& Clarke, 2010). Appraisal processes are crucial in the process of stress (Lazarus \& Folkman, 1984) and they determine distress and eustress experiences. In this way, a stressor can be appraised as a source of threat or anticipation of harm (distress), or as a source of challenge and opportunity (eustress) (Lazarus, 1993).

Some research has already studied stressors frequently reported as sources of distress (e.g., time pressure, role and work overload, excessive paperwork, unfair organizational practices, insecure relationships, or monotonous work that hinders personal development (Ivancevich \& Matteson, 1984; Türetgen, Berk, Basbug, \& Unsal, 2012) to be appraised as sources of distress. Also, Vagg and Spielberger (1998), studied the perceived intensity (severity) of working circumstances that may often result in psychological strain, recognizing job pressure and lack of support as key dimensions of distress in the workplace (Vagg \& Spielberger, 1999); however, they did not incorporate a positive approach of eustress appraisal, that impedes evaluating the simultaneous appraisal of distress and eustress for the same events.

Other studies counterbalance the predominant negative approach to stress by contemplating its positive side (Lazarus \& Folkman, 1984), distinguishing between challenge and hindrance work stressors (Cavanaugh et al., 2000). Yet, threat and challenge are not necessarily mutually exclusive (Lazarus \& Folkman, 1984) since they may coexist and occur simultaneously in response to the same demand (McGowan, Gardner, \& Fletcher, 2006). A rather limited number of studies show that the same demand can be appraised both as distress and as eustress and have positive and negative effects (Gibbons, Dempster \& Moutray, 2009; Kozusznik, Rodríguez, \& Peiró, 2012). They identify demands that can be sources of work distress and strain (Coomber, Todd, Park, Baxter, Firth-Cozens, \& Shore, 2002; Greenblatt, 2002; Michaels, Handfield-Jones, H., Axelrod, 2001; Relationships source of workplace stress, 2002) and simultaneously a source of eustress (Rodríguez et al., 2013). However, the hierarchy (or the severity) of stressful demands at work has not been explicitly studied.

The paucity of research on the simultaneous appraisal of work-related demands as eustress and distress may be due to the lack of measurement methods to adequately assess them. A recently introduced measure of eustress and distress appraisal (Valencia Eustress Distress Appraisal Scale, VEDAS) (Rodríguez et al., 2013) follows the recent advances in the study of stress by incorporating both a positive perspective and the traditional negative perspective in stress appraisal (Kozusznik et al., 2012; Podsakoff et al., 2007) and makes it possible to measure both eustress and distress appraisal of the same demands in different occupations.

Further research on sources of work-related distress and eustress is needed and recent advances in measurement theory (i.e., the Rasch Analysis, RA) should be applied for identifying the hierarchy of work-related stressors, uncovering the extent to which each of the demanding situations can simultaneously be appraised as source of distress and eustress.

\section{Rasch Calibration: A Modern Approach to Uncovering Hierarchy of Work-Related Sources of Distress and Eustress.}

The recent developments in measurement can address some limitations in the study of the sources of work-related distress and eustress. First, these studies have relied on Likert-type scale measurements (Anshel, Kang, \& Jubenville, 2013), treating the distances between each response scale options as equal. Because ordinal scale data are not additive (Anshel et al., 2013; Bond \& Fox, 2001; Zhu, 1996), the total score of the scale items can be biased (Bond \& 
Fox, 2001). RA can complement traditional approaches to measurement by overcoming these limitations and transforming ordinal scales into true-interval where suitable parametric tests can be applied (Anshel et al., 2013).

Second, the difficulty level of scale items is not controlled and person's scores (or ability levels) are usually obtained by summing up the answers to all the items in the scale, assuming that all items in the scale have the same or similar levels of difficulty. However, there is no reason to treat different items in a scale as identically contributing to the scale (Zhu, 1996), since they can represent different levels of the scale's construct. Therefore, since Classical Test Theory is unable to control items' difficulty (Anshel et al., 2013) it has been impossible to specify whether the fact that some stressors are rated as important sources of distress/eustress stems from the actual characteristics of the stressors or from an overall tendency of the persons who rated them to appraise all demands as distress/eustress.

There is a need to apply advances in measurement to the study of occupational stress. RA can contribute to assessing sources of stress (Anshel et al., 2013) and determine the hierarchy of work-related sources of distress and/or eustress. It would be beneficial for organizations to get the information about the most/least important sources of distress and/or eustress at work to apply preventive measures and promote well-being and performance at work. With this in mind, the purpose of the present study is to uncover the hierarchy of work-related demands that can be appraised both as distress and eustress by calibrating the VEDAS (Rodríguez et al., 2013) using RA.

\section{Method}

\section{Participants and Procedure}

A sample of 603 employees (109 male, 484 female; 10 participants failed to specify their sex) in Public Social Services in the Valencian Community (response rate $75 \%$ ) completed the questionnaire. All participants were Spanish, predominantly from a middle-class socioeconomic background (INE, 2010), between 20 and 70 years old $(M=37.52, \mathrm{SD}=8.62)$. The sex composition of our convenience sample ( $82 \%$ women) reflects the real sex distribution in the social services sector in the Valencian Community (IVE, 2010). Participation was voluntary and anonymous.

\section{Measures}

VEDAS. The VEDAS (Rodríguez et al., 2013) is composed of 20 items representing demanding situations that can be appraised as both distress and eustress, providing total scores for distress and eustress appraisals. Both scales are essentially unidimensional and tap four related subdimensions: relationships (dominant dimension), personal accountability, homework balance, and workload (secondary dimensions). Every item can be rated both as threatening and as challenging/opportunity on two 6-point Likert response scales, ranging from 1 (clearly, it is not a source of threat) to 6 (clearly, it is a source of threat) for distress, and from 1 (clearly, it is not a source of challenge/opportunity) to 6 (clearly, it is a source of challenge/ opportunity) for eustress appraisal scale. The VEDAS has good psychometric properties (Rodríguez et al., 2013): a) Cronbach's alpha values was around .90 for distress/eustress composite scores, b) the confirmatory factor analysis supported the essential unidimentionality of the VEDAS in both the distress and eustress dimensions, c) the independence of the composite eustress and distress scores was supported by a low correlation between the two composite 
scales of the VEDAS, and d) the convergent validity of the VEDAS scales indicated significant relationships between the VEDAS subscales and related constructs of burnout and work engagement (Maier, Waldstein, \& Synowski, 2003; Schaufeli \& Van Rhennen, 2006); significant positive correlations were found between the composite score of the appraisal of distress and burnout, a negative correlation between the composite score of the appraisal of eustress and burnout, and a positive correlation between the composite score of the appraisal of eustress and work engagement. An example of an item is "Feeling isolated".

\section{Analyses}

Rasch Rating Scale Model (RSM) (Andrich, 1978), a version of RA for Likert-type scales, was performed using WINSTEPS (Linacre, 2006). Several analytical steps were followed:

(1) Model-data fit: acceptable Infit and Outfit values for items and persons are between $0.5-1.50$ (Linacre \& Wright, 1999);

(2) Response scale functioning: regular observation distribution, acceptable Outfit statistics for each category, the order of thresholds, a distance of 1.4-5 logits between response options (Linacre, 1999);

(3) Analysis of item-person map: showing both item locations and the person ability on the same continuum;

(4) Item location parameters' estimation: the larger the logit score, the lesser source of distress/ eustress is perceived by the individuals;

(5) Individual's location estimation: larger scores indicate higher levels of distress/eustress appraisal;

(6) Proper targeting: the correspondence between the subjects' and items' locations; their means and distributions; should be similar, and the mean person/item locations - around zero (Pallant \& Tennant, 2007);

(7) Replicability of the placement of persons and items: holds when Item and Person Separation reliability indexes values are $>2.0$ (Wright \& Masters, 1982);

(8) Unidimensionality: tested through a principal component analysis of the residuals. A component explaining more than 2 units of unexplained variance may be indicating the existence of a secondary subdimension (Linacre \& Wright, 1999);

(9) Differential test functioning: test is biased when items show statistical significance $(p<.001)$ (Linacre, 1999);

\section{Results}

\section{Initial Analyses}

The model Infit and the outlier-sensitive Outfit statistics identified two misfitting items the 20-item VEDAS (see Table 1). Also, the functioning of the original 6-point response scale was not satisfactory: the response categories for did not follow the expected monotonical progression of rated levels from category 1 to category 6. Specifically, this was the case of the two adjacent categories 3 and 4 , in the distress scale, and of the three categories $(2,3$, and 4$)$ in the eustress scale. Also, examination of the probability curves revealed that on both the distress and eustress scales, Categories 3, 4 and 5 were mixed-up; Categories 4 and 5 were the most probable categories only across a very small section of the variable, whereas Category 3 was never the most likely category to be endorsed. Categories 2 and 3 are the most redundant 
visually for both distress and eustress. Finally, the response options were not appropriately distanced from one another, since the distances between the thresholds did not reach 1.4 logits (Linacre, 1999).

The best discrimination of the rating scale and the best data-model fit was achieved by collapsing the rating categories for the distress and eustress scales into a parsimonious 3-point scale and excluding the two misfitting items (see Table 1 and Figure 1). We should note that before reaching this 3-point solution, we tried other solutions to achieve the best discrimination of the rating scale and the best data-model fit. a) combining rating Categories 3 and 4 as the closest to each other; b) merging categories 1 with 2 , and categories 5 with 6 , and then c) merging options 2 with 3, and 4 with 5. These solutions, however, did not turn out to be the best ones, which suggests that the two middle options 3 and 4 are functioning in practice as two intermediate options.

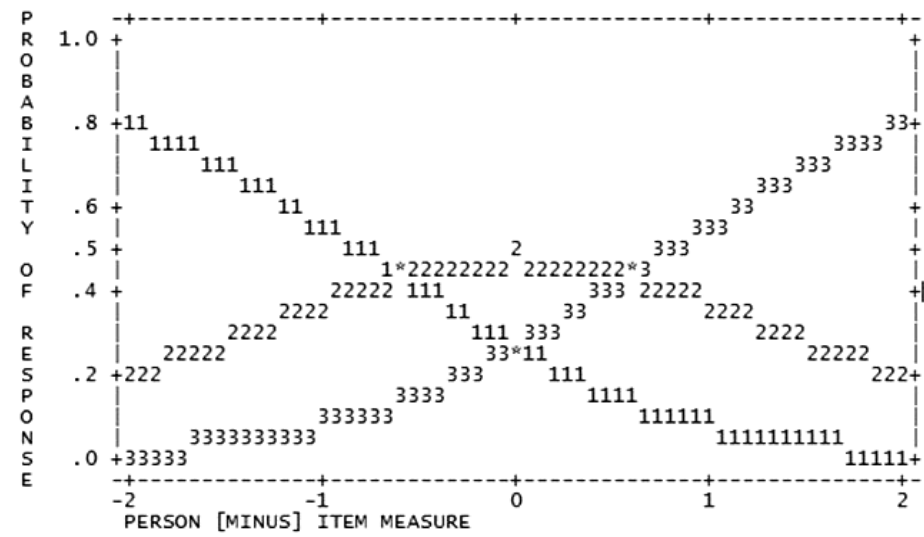

Note. The same tendency appears in the case of the eustress scale; however, for the sake of conciseness, we present here only the results for the distress scale.

Figure 1. Analysis of the modified VEDAS distress 3-point rating scale categories. 


\begin{tabular}{|c|c|c|c|c|c|c|c|c|c|}
\hline 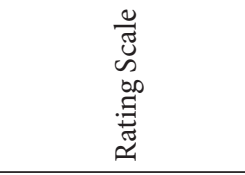 & \multicolumn{2}{|c|}{ 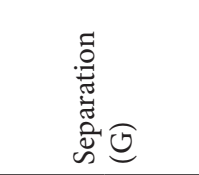 } & \multicolumn{2}{|c|}{ 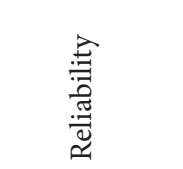 } & \multirow[t]{2}{*}{ 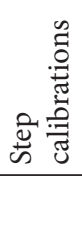 } & \multirow[t]{2}{*}{ 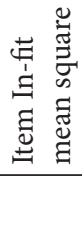 } & \multirow[t]{2}{*}{ 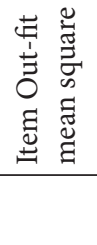 } & \multirow[t]{2}{*}{ 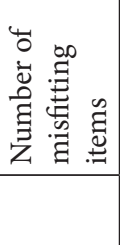 } & \multirow[t]{2}{*}{ 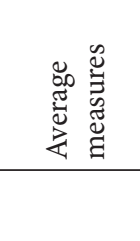 } \\
\hline & Person & Item & Person & Item & & & & & \\
\hline \multicolumn{10}{|l|}{ Distress } \\
\hline $\begin{array}{l}\text { Original } \\
\text { six-point scale }\end{array}$ & 2.56 & 6.86 & .87 & .98 & 1.00 & 1.06 & $2(1,2)$ & ordered & disordered \\
\hline $\begin{array}{l}\text { Three-point scale } \\
\text { (combining } 1 \\
\text { and } 2,3 \text { and } 4,5 \\
\text { and } 6 \text {; removing } 2 \\
\text { misfitting items) }\end{array}$ & 2.25 & 6.75 & .84 & .98 & 1.00 & 1.02 & 0 & ordered & ordered \\
\hline \multicolumn{10}{|l|}{ Eustress } \\
\hline $\begin{array}{l}\text { Original } \\
\text { six-point scale }\end{array}$ & 2.25 & 11.64 & .83 & .99 & 1.02 & 1.04 & $2(1,2)$ & ordered & disordered \\
\hline $\begin{array}{l}\text { Three-point scale } \\
\text { (combining } 1 \\
\text { and } 2,3 \text { and } 4,5 \text {, } \\
\text { and } 6 \text {; removing } 2 \\
\text { misfitting items }{ }^{*} \text { ) }\end{array}$ & 2.12 & 11.04 & .82 & .99 & 1.01 & 1.00 & 0 & ordered & ordered \\
\hline
\end{tabular}

Note. ${ }^{*}$ Removing item 1 , which did not fit in the distress scale, and item 2 , which did not fit in either the distress or eustress scales (we eliminated both items from both scales to maintain the commensurability of the two scales); The alternative solutions were guided by the goals of: (a) ensuring that all items have good fit; ( $b$ ) ensuring good functioning of the rating scale categories; (c) maximizing separation; and (d) retaining items.

Table 1. Summary of Changes in Person and Item Separation and Reliability as a Result of Collapsing Distress and Eustress Rating Scale Categories and Removing Misfitting Items

\section{Hierarchy of Eustress and Distress}

As depicted in the Table 2, the greatest source of distress was represented by the items "Having to adopt a negative role (such as sacking someone)" and "Not being able to 'switch off' at home". The "Lack of practical support from others outside work". generated less distress. All five items in the Relationships distress factor belonged to the group of the most important sources of distress. Four out of five items in the Home-Work Balance factor generated least distress. The greatest source of eustress was "Having to take risks", and the situation that produced the least eustress was "Not being able to 'switch off' at home" (See Table 3). All four items in the "Personal Accountability" factor were the greatest sources of eustress, whereas three out of five items from the "Home-Work Balance" factor reflected least eustress. All five items in the "Relationships" factor as eustress were considered minor sources of eustress. Interestingly, the situations that coincide in producing least distress and least eustress are "Absence of emotional support from others outside work" and "My partner's negative attitude towards my job and career". The rest of the items were spread around the mean value of difficulty. 


\begin{tabular}{|c|c|c|c|c|c|c|}
\hline Order $\#^{1}$ & Item \# & & $\begin{array}{l}\text { Calibration } \\
\text { logits }\end{array}$ & $\begin{array}{c}\text { SE } \\
\text { logits }\end{array}$ & $\begin{array}{l}\text { Infit } \\
\mathrm{MnSq}\end{array}$ & $\begin{array}{l}\text { Outfit } \\
\text { MnSq }\end{array}$ \\
\hline & & The situation most frequently identified as distress & & & & \\
\hline 9 & 18. & $\begin{array}{l}\text { Having to adopt a negative role } \\
\text { (such as sacking someone). }\end{array}$ & $.61^{*}$ & .08 & .95 & .95 \\
\hline 9 & 3. & Not being able to ,switch off' at home & .58 & .08 & 1.13 & 1.09 \\
\hline 8 & 11. & Being undervalued & .44 & .07 & .91 & .80 \\
\hline 7 & 8. & $\begin{array}{l}\text { Conflicting job tasks and demands in the role } \\
\text { I play }\end{array}$ & .36 & .07 & .92 & .98 \\
\hline 7 & 9. & Discrimination and favouritism & .30 & .07 & .98 & .92 \\
\hline 7 & 13. & $\begin{array}{l}\text { Inadequate feedback about my own } \\
\text { performance }\end{array}$ & .24 & .07 & .85 & .94 \\
\hline 7 & 17. & $\begin{array}{l}\text { Dealing with ambiguous } \\
\text { or ,delicate' situations }\end{array}$ & .22 & .07 & .95 & .95 \\
\hline 7 & 10. & Feeling isolated & .22 & .07 & .96 & .86 \\
\hline 6 & 20. & Pursuing a career at the expense of home life & .20 & .07 & 1.16 & 1.15 \\
\hline 6 & 4. & $\begin{array}{l}\text { Inadequate or poor quality } \\
\text { of training/management development. }\end{array}$ & .20 & .07 & 1.20 & 1.36 \\
\hline 6 & 5. & Lack of social support by people at work. & .09 & .07 & .95 & 1.07 \\
\hline 5 & 7. & Having to work very long hours & .06 & .07 & 1.00 & .98 \\
\hline 5 & 12. & Having to take risks & .03 & .07 & .96 & 1.13 \\
\hline 4 & 19. & Implications of mistakes you make. & -.09 & .07 & 1.09 & 1.19 \\
\hline 3 & 15. & $\begin{array}{l}\text { Demands that work makes on my private/ } \\
\text { social life }\end{array}$ & -.66 & .07 & .98 & 1.03 \\
\hline 3 & 14. & $\begin{array}{l}\text { Absence of emotional support from others } \\
\text { outside work }\end{array}$ & -.76 & .07 & .91 & .90 \\
\hline 2 & 6. & $\begin{array}{l}\text { My partner's negative attitude towards my job } \\
\text { and career }\end{array}$ & -.91 & .07 & 1.18 & 1.08 \\
\hline \multirow[t]{2}{*}{1} & 16. & $\begin{array}{l}\text { Lack of practical support from others outside } \\
\text { work }\end{array}$ & -1.13 & .07 & .99 & .99 \\
\hline & & The situation less frequently identified as distress & & & & \\
\hline
\end{tabular}

Note. ${ }^{1}$ The number indicates the order that corresponds to the item after calibrating the scale with the Rating Model. ${ }^{*}$ The higher the logits score, the most frequently the item is identified as a source of distress by the respondents.The sign of the average values has been inverted for the sake of clarity.

Table 2. The ordered distress appraisal scale. 


\begin{tabular}{|c|c|c|c|c|c|c|}
\hline Order $\#^{1}$ & Item \# & & $\begin{array}{l}\text { Calibration } \\
\text { logits }\end{array}$ & $\begin{array}{c}\text { SE } \\
\text { logits }\end{array}$ & $\begin{array}{l}\text { Infit } \\
\mathrm{MnSq}\end{array}$ & $\begin{array}{l}\text { Outfit } \\
\text { MnSq }\end{array}$ \\
\hline & & The situation most frequently identified as eustress & & & & \\
\hline 10 & 12. & Having to take risks & $1.73^{*}$ & .07 & 1.15 & 1.19 \\
\hline 9 & 17. & $\begin{array}{l}\text { Dealing with ambiguous or ,delicate } \\
\text { situations }\end{array}$ & 1.50 & .07 & .99 & 1.07 \\
\hline 8 & 19. & Implications of mistakes you make. & 1.33 & .07 & 1.06 & 1.13 \\
\hline 7 & 8. & $\begin{array}{l}\text { Conflicting job tasks and demands in the role } \\
\text { I play }\end{array}$ & .71 & .06 & .84 & .81 \\
\hline 7 & 18. & $\begin{array}{l}\text { Having to adopt a negative role } \\
\text { (such as sacking someone). }\end{array}$ & .66 & .06 & 1.04 & 1.05 \\
\hline 6 & 4. & $\begin{array}{l}\text { Inadequate or poor quality of training/ } \\
\text { management development. }\end{array}$ & .21 & .07 & 1.17 & 1.21 \\
\hline 5 & 15. & $\begin{array}{l}\text { Demands that work makes on my private/ } \\
\text { social life }\end{array}$ & -.28 & .07 & 1.00 & 1.06 \\
\hline 5 & 13. & $\begin{array}{l}\text { Inadequate feedback about my own } \\
\text { performance }\end{array}$ & -.32 & .07 & .92 & .84 \\
\hline 5 & 16. & $\begin{array}{l}\text { Lack of practical support from others outside } \\
\text { work }\end{array}$ & -.34 & .07 & .99 & 1.01 \\
\hline 4 & 5. & Lack of social support from people at work. & -.36 & .07 & .89 & .85 \\
\hline 4 & 11. & Being undervalued & -.40 & .07 & .96 & .84 \\
\hline 4 & 7. & Having to work very long hours & -.42 & .07 & 1.00 & .98 \\
\hline 4 & 20. & Pursuing a career at the expense of home life & -.46 & .07 & 1.13 & 1.12 \\
\hline 3 & 10. & Feeling isolated & -.58 & .07 & .97 & .89 \\
\hline 3 & 9. & Discrimination and favouritism & -.60 & .07 & .95 & .93 \\
\hline 2 & 14. & $\begin{array}{l}\text { Absence of emotional support from others } \\
\text { outside work }\end{array}$ & -.67 & .07 & .92 & .99 \\
\hline 2 & 6. & $\begin{array}{l}\text { My partner's negative attitude towards my job } \\
\text { and career }\end{array}$ & -.76 & .08 & 1.08 & .98 \\
\hline \multirow[t]{2}{*}{1} & 3. & Not being able to , switch off' at home & -.93 & .08 & 1.19 & 1.08 \\
\hline & & The situation less frequently identified as eustress & & & & \\
\hline
\end{tabular}

Note. ${ }^{I}$ The number indicates the order that corresponds to the item after calibrating the scale with the Rating Model. *The higher the logits score, the most frequently the item is identified as a source of eustress by the respondents. The sign of the average values has been inverted for the sake of clarity.

\section{Table 3. The ordered eustress appraisal scale}

\section{Additional results}

The precision of the VEDAS 18-item set was assessed by calculating the standard error (SE) for each ability-score level. In the middle of the ability scale, the SEs were low around .34, indicating high reliability (Linacre \& Wright, 1999). At the high and low end of scoring, the 
SEs were slightly higher. Although the spread of the items is large and basically normal on both scales (see Figure 2), there were minor gaps in the high-end scores and around -1,5, 0,5 and 2,5 logit in distress), as well as in low-end scores and around -2,5, - 0,5 and 1,5 on the eustress scale. Also, there were some "measure-similar items" (Wright \& Stone, 2004) on distress and eustress scales measuring respondents at similar locations.

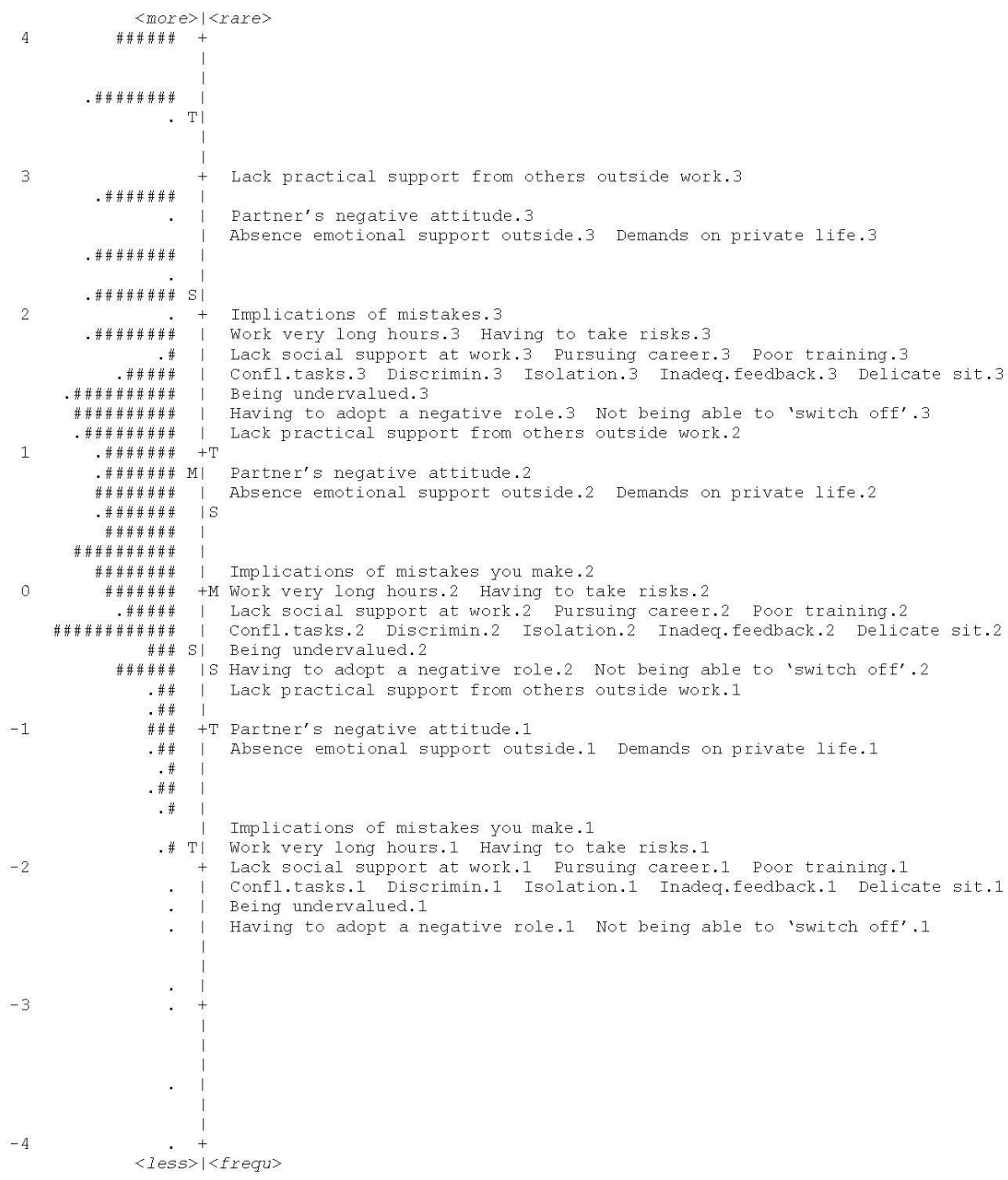

Note. Each "\#" is 3 people. Each "." Is 1 to 2 people. "More/less" means "more/less distress appraisal". "Rare/ frequ" means rerely/frequently appraised as distress". The same pattern appears in the case of the dustress scale; however, for the sake of conciseness, we present here only the results for the distress scale.

Figure 2. Person-item map by thresholds for the revised VEDAS distress scale. 
Additionally, results indicate a secondary dimension explaining 2.4 units of unexplained variance with a relatively weak impact on subjects' responses in both in the distress and eustress scales. For distress, the items forming part of this secondary component are related to adopting decisions involving other people at work, taking risks, dealing with delicate situations, implications of one's mistakes and, on the other pole, lack of social support. In the eustress scale, the secondary component has similar meaning as in case of the distress scale; its items also relate to individual performance in delicate situations involving others at work and lack of social support. Therefore, the additional sub-dimension in both scales refers to stressors related to relationships with, support of, and influence on other people.

Finally, invariance was tested by estimating item calibration differences for the sample split randomly in two groups and it showed no outliers that exceed the approximately $95 \%$ confidence bands and all items' distribution around the commonality line. An additional analysis of invariance of the items' calibration in the sample divided by sex did not show any items beyond the confidence limit either, showing similarity in distress and eustress appraisals for male and female professionals. These facts indicate that there is no test bias, items' calibration is invariant, and differential test functioning is rejected.

\section{Discussion}

The purpose of this paper was to calibrate the VEDAS (Rodríguez et al, 2013) using the recent advances in measurement theory (i.e., RA) to uncover the hierarchy of work-related demands that simultaneously can be sources of distress and eustress (Folkman, 1997; McGowan et al., 2006).

The results show that special attention should be given to learning how to deal with and re-appraise demanding situations concerning work, that happen at work. The importance of "switching off at home", draws our attention to successfully managing life-work interference related to work organization, modalities, flexibility, and promoting effective recovery after work (Sonnentag \& Zijlstra, 2006). Situations involving personal accountability and the consequences of one's actions at work should be stimulated, as they may have positive consequences for employees. Preventing problems related to relationships seems to be the most efficient way to simultaneously prevent distress and stimulate eustress at work. Additionally, the results suggest adding some items with certain "intensity" levels. If a briefer version of the VEDAS is to be constructed to measure overall distress and eustress appraisal levels, the results identify the items that could be excluded.

\section{Contributions, limitations, and implications}

The contribution of this study is that it examines work-related demands that simultaneously can be sources of distress and eustress (McGowan et al., 2006) expanding the traditional approach to stress as something negative (Kozusznik et al., 2012; Podsakoff et al., 2007). It also expands the knowledge on individual eustress and distress appraisal (Cavanaugh et al., 2000; Rodríguez et al., 2013) by showing the hierarchy of demands at work, not yet explicitly studied. Finally, it applies the recent advances in measurement theory, RA that overcomes the limitation of the Likert-type scales.

This study was limited by a relative thinness of the sample at the lowest levels of - distress and at the highest levels of eustress producing larger standard errors and decreased stability of the item estimates at these extremes of the scales. 
There are several practical implications of the present study. First, in managerial practice, the hierarchy of stress makes it possible to concentrate on the most important demanding situations that should be prevented or stimulated. Second, in academics, it shows that the use of RA to check the functioning of the response scale of the existing or the newly created tests and provide empirical evidence about the recommended number of response options (instead of merely assuming it theoretically) could form part of a routine scale development process. Also, RA can be useful in searching for possible additional psychometric dimensions underlying the questionnaire, ensuring that there is cross-cultural equivalence in meaning in different language versions of questionnaires, and making it possible to carry out parametric analyses without breaking the assumption of the need for continuous-level data. In sum, improving I/O measurement methods provides an opportunity for I/O psychology to increase the quality of research, produce cutting-edge science by constructing more effective and rigorous questionnaires with strong explanatory and predictive power. The emergence of the RA is one of the greatest recent advances in measurement (Zhu, 1996). There is no doubt that it allows for studying eustress and distress appraisal from a novel perspective and it opens new ways for future research.

\section{References}

Andrich, D. (1978). A rating formulation for ordered response categories. Psychometrika, Vol. 43, pp. 561-573. ISSN 1860-0980 (Online). Available from: doi:10.1007/BF02293814

Anshel, M. H., Kang, M., \& Jubenville, C. (2013). Sources of acute sport stress scale for sport officials: Rasch calibration. Psychology of Sport and Exercise, Vol. 14, pp. 362-370. ISSN: 1469-0292. Available from: doi:10.1016/j.psychsport.2012.12.003

Bond, T.G, \& Fox, C.M. (2001). Applying the Rasch model: fundamental measurement in the human sciences. Mahwah, NJ: LEA. ISBN: 978-0805854626.

Cavanaugh, M. A., Boswell, W. R., Roehling, M. V., \& Boudreau, J. W. (2000). An empirical examination of self-reported work stress among U.S. managers. Journal of Applied Psychology, Vol. 85, pp. 65-74. ISSN: 1939-1854. Available from: doi:10.1037/0021-9010.85.1.65

Coomber, S., Todd, C., Park, G., Baxter, P., Firth-Cozens, J., \& Shore, S. (2002). Stress in UK intensive care unit doctors. British Journal of Anaesthesia, Vol. 89, pp. 873-881. ISSN: 1471-6771. Available from: doi:10.1093/bja/aef273

Eurofound and EU-OSHA (2014), Psychosocial risks in Europe: Prevalence and strategies for prevention, Publications Office of the European Union, Luxembourg. ISBN: 978-92-897-1218-7. Available from: https://osha.europa.eu/en/tools-and-publications/publications/reports/psychosocial-risks-euprevalence-strategies-prevention

Gabriel, A. S., Diefendorff, J. M., \& Erickson, R. J. (2011). The relations of daily task accomplishment satisfaction with changes in affect: A multilevel study in nurses. Journal of Applied Psychology, Vol. 96, pp. 1095-1104. ISSN: 1939-1854. Available from: doi:10.1037/a0023937

Ganster, D.C., \& Rosen, C.C. (2013). Work stress and employee health: A multidisciplinary review. Journal of Management, Vol. 39, pp. 1085-1122. ISSN: 1557-1211. Available from: doi:10.1177/0149206313475815

Gibbons, C., Dempster, M., \& Moutray, M. (2009). Index of sources of stress in nursing students: A confirmatory factor analysis. Journal of Advanced Nursing, Vol. 65, No. 5, pp. 1095-1102. ISSN: 1365-2648. Available from: doi:10.1111/j.1365-2648.2009.04972.x

Greenblatt, E. (2002). Work/life balance: Wisdom or whining. Organizational Dynamics, Vol. 31, pp. 177-193. ISSN: 0090-2616. 
Griffin, M. A., \& Clarke, S. (2010). Stress and well-being at work: In S. Zedeck (Ed.), APA handbook of industrial and organizational psychology (Vol. 3, pp. 359-397). Washington, DC: American Psychological Association. ISBN: 9781433808388.

Instituto Nacional de Estadística (INE) (2010), Encuesta anual de coste laboral. Serie 2008-2010, Instituto Nacional de Estadística, Available from: www.ine.es/jaxi/tabla.do (accessed 1 October 2011).

Institut Valencia d'Estadistica (IVE), (2010) Encuesta de Poblacion Activa, Available from: http://www. ive.es/portal/page/portal/IVE_PEGV/CONTENTS/epa /ini_cas.htm (accesed 30 May 2011).

Ivancevich, J. M., \& Matteson, M. T. (1984). A type AB person-work environment interaction model for examining occupational stress and consequences. Human Relations, Vol. 37, No. 7, pp. 491-513. ISSN: 1741-282X. Available from: doi:10.1177/001872678403700701

Kozusznik, M., Rodríguez, I., \& Peiró, J. M. (2012). Cross-national outcomes of stress appraisal. Cross Cultural Management, Vol. 19, No. 4, pp. 507-525. ISSN: 1352-7606. Available from: doi:10.1108/13527601211269996

Lazarus, R. S., \& Folkman, S. (1984). Stress, appraisal, and coping. New York: Springer. ISBN: 9780826141910.

Lazarus, R.S. (1993). From psychological stress to the emotions: a history of changing outlooks. Annual Review of Psychology, Vol. 44, pp. 1-21. ISSN: 0066-4308. Available from: doi:10.1146/annurev. ps.44.020193.000245

Linacre, J. M. (1999). Investigating rating scale category utility. Journal of Outcome Measurement, Vol. 3, No. 2, pp. 103. ISSN: 1090-655X.

Linacre, J. M. (2006). WINSTEPS: Rasch measurement computer program. Chicago: Winsteps.Com. Available from http://www.winsteps.com/

Linacre, J. M., \& Wright, B. (1999). A user's guide to WINSTEPS. Chicago: MESA Press. ISBN: 0-941938-03-4.

Maier, K. J., Waldstein, S., \& Synowski, S. (2003). Relation of cognitive appraisal to cardiovascular reactivity, affect and task engagement. Annals of Behavioral Medicine, 26, 32-41. doi:10.1207/ S15324796ABM2601_05

Maslach, C., Jackson, S. E., \& Leiter, M. P. (1996). Maslach Burnout Inventory. Manual (3rd ed.). Palo Alto, CA: Consulting Psychologists Press. ISBN: 978-9996345777.

McGowan, J., Gardner, G. \& Fletcher, R. (2006). Positive and negative affective outcomes of occupational stress. New Zealand Journal of Psychology, Vol. 35, pp. 92-98. ISSN: 0112-109X.

Michaels, E., Handfield-Jones, H., \& Axelrod, B. (2001). The war for talent. Boston, MA: Harvard Business School Press. ISBN: 978-1578514595.

Pallant, J. F., \& Tennant, A. (2007). An introduction to the Rasch measurement model: An example using the hospital anxiety and depression scale (HADS). British Journal of Clinical Psychology, Vol. 46, No. 1, pp. 1-18. ISSN: 2044-8260. Available from: doi:10.1348/014466506X96931

Podsakoff, N. P., LePine, J. A., \& LePine, M. A. (2007). Differential challenge stressor-hindrance stressor relationships with job attitudes, turnover intentions, turnover, and withdrawal behavior: A metaanalysis. Journal of Applied Psychology, Vol. 92, No. 2, pp. 438-454. ISSN: 1939-1854. Available from: doi:10.1037/0021-9010.92.2.438

Relationships source of workplace stress. (2002, September 12). Korea Herald. Available from: http:// search.proquest.com/docview/281430933? accountid14777

Rodríguez, I., Kozusznik, M. W., \& Peiró, J. M. (2013). Development and validation of the Valencia Eustress-Distress Appraisal Scale. International Journal of Stress Management, Vol. 20, No. 4, pp. 279-308. ISSN: 1573-3424. doi:10.1037/a0034330

Salanova, M., \& Schaufeli, W. B. (2000). Exposure to burnout and its relationship to burnout. Behavior and Information Technology, Vol. 19, pp. 385-392. ISSN: 1362-3001. Available from: doi:10.1080/014492900750000081 
Schaufeli, W. B., \& Van Rhenen, W. (2006). Over de rol van positieve en negatieve emoties bij het welbevinden van managers: Een studie met job-related Affective Well-Being Scale (JAWS) [About the role of positive and negative emotions in managers'wellbeing: A study using the Jobrelated Affective Well-being Scale (JAWS)]. Gedrag en Organisatie, 19, 323-344.

Scheck, C. L., Kinicki, A. J., \& Davy, J. A. (1997). Testing the mediating processes between work stressors and subjective well-being. Journal of Vocational Behavior, Vol. 50, pp. 96-123. ISSN: 0001-8791. Available from: doi:10.1006/jvbe.1996.1540

Schwarzer, R., \& Knoll, N. (2003). Positive coping: Mastering demands and searching for meaning. In S. J. Lopez \& C. R. Snyder (Eds.), Handbook of positive psychological assessment. A handbook of models and measures (pp. 393-409). Washington, DC: American Psychological Association. ISBN: 978-1-55798-988-8.

Sonnentag, S., \& Zijlstra, F. (2006). Job characteristics and off-job activities as predictors of need for recovery, well-being, and fatigue. Journal of Applied Psychology, Vol. 91, No. 2, pp. 330-350. ISSN: 1939-1854. Available from: doi:10.1037/0021-9010.91.2.330

Türetgen, I. Ö., Berk, Ö., S., Basbug, G., \& Unsal, P. (2012). The Development of the Job Stressor Appraisal Scale as Part of the Job Stress Battery. European Journal of Psychological Assessment, Vol. 28, No. 2, pp. 147-153. ISSN: 2151-2426. Available from: doi:10.1027/1015-5759/a000103

Wright, B. D., \& Masters, G. N. (1982). Rating scale analysis. rasch measurement. Chicago: MESA Press. ISBN 0-941938-01-8.

Wright, B. D., \& Stone, M. H. (2004). Making measures. Chicago: The Phaneron Press. ISBN: 978-1930847392.

$\mathrm{Zhu}, \mathrm{W}$. (1996). Should total scores from a rating scale be used directly? Research Quarterly for Exercise and Sport, Vol. 67, pp. 363-372. ISSN: 168-3824.

Malgorzata W. Kozusznik malgorzata.kozusznik@uv.es Universidad de Valencia, IDOCAL

Susana Lloret Universidad de Valencia, IDOCAL

Isabel Rodríguez Universidad de Valencia, IDOCAL

José M. Peiró jose.m.peiro@uv.es Universidad de Valencia, IDOCAL and IVIE 